\title{
Estados Unidos y el régimen internacional de propiedad intelectual*
}

$\mathrm{D}$ urante las negociaciones comerciales de la Ronda de Tokio (1973-1979), Estados Unidos y la Comunidad Europea propusieron incluir en la agenda el tema sobre propiedad intelectual, al llamar la atención sobre el comercio de mercancías falsificadas ${ }^{1}$ (y poner en la agenda un borrador de acuerdo con el tema). ${ }^{2}$ No obstante, ha sido en el transcurso de las últimas dos décadas cuando este tema ha cobrado una mayor relevancia, fundada en gran parte en el reconocimiento de la estrecha relación entre la propiedad intelectual y el comercio internacional. ${ }^{3}$ De esta manera, un tema que parecía llamar la atención sólo de algunos académicos o legistas y ser de competencia casi exclusiva de un foro multilateral, como la Organización Mundial de la Propiedad Intelectual (oMPI), pronto se convirtió en materia de discusión a los niveles más altos.

Los intentos contemporáneos más insistentes por proteger los derechos de propiedad intelectual provienen de Estados Unidos, que ya en su Ley de Comercio (de 1984) había introducido algunos aspectos que condicionaban el trato comercial a países en desarrollo, otorgando las preferencias sólo a aquellos países que se comprometieran a hacer más efectiva la protección de los derechos de propiedad intelectual en sus territorios respectivos. ${ }^{4}$ Además, otros países desarrollados, como Japón y los de la Unión Europea, recientemente habían apoyado las propuestas de Estados Unidos. Esto dio como resultado que se iniciara a partir del 5 de febrero de 1987 la negociación que derivó en el Acuerdo sobre los Aspectos de los Derechos de Propiedad Inte-

* Este artículo es parte del proyecto financiado por el PROMEP/103.5/03/2580.

** Profesor investigador del Departamento de Estudios del Pacífico, de la Universidad de Guadalajara.

ORCID http://orcid.org/0000-0003-0344-6895 lectual Relacionados con el Comercio (ADPIC), ${ }^{5}$ cuyo texto final fue aprobado en Marrakech durante el mes de abril de $1994 .^{6}$

Después de la entrada en vigor del ADPIC, en 1995, ¿qué tan reforzada está en el ámbito internacional la protección de los derechos de propiedad intelectual?, ¿se pueden identificar claramente principios, normas, reglas y procedimientos de toma de decisiones que lo caractericen? En el presente artículo se tratará de dar respuesta a estas preguntas y se indagará el papel de Estados Unidos en la negociación del ADPIC, que representa al régimen internacional ${ }^{7}$ para la protección de los derechos de propiedad intelectual en el mundo.

\section{¿Q ué son los derechos de propiedad intelectual?}

La propiedad intelectual se concibe generalmente como los derechos legales sobre nuevas ideas. Dichos derechos en su mayor parte son cubiertos a través de las leyes que protegen las patentes, las marcas comerciales, los diseños industriales y los derechos de autor. Esta definición refleja una concepción ampliada de la propiedad intelectual, en oposición a la visión más antigua que se refería sólo a los derechos de autor, mientras que las patentes, las marcas comerciales y los diseños industriales se consideraban básicamente como propiedad industrial. ${ }^{8}$

Una patente se define como un documento, extendido por una oficina de gobierno, que describe un invento y crea una situación legal en la cual el invento patentado solamente puede ser trabajado con la autorización expresa del propietario de la patente. La protección del invento se limita generalmente a un período de entre 15 y 20 años. Las condiciones 
que el objeto de la patente debe reunir son las de que realmente manifieste un paso inventivo, contenga alguna novedad y tenga una aplicación industrial.

Las marcas comerciales se definen como los signos distintivos que sirven para diferenciar los bienes y servicios de una determinada empresa del mismo tipo de bienes y servicios de los competidores. La protección de las marcas comerciales tiene como objetivo estimular y garantizar una competencia leal $y$, a la vez, proteger a los consumidores haciendo que puedan elegir con conocimiento de causa entre diversos productos o servicios. La protección puede durar indefinidamente, siempre que el signo en cuestión siga siendo distintivo.

Los diseños industriales (o modelos) son títulos acreditados para respaldar una propiedad industrial. Estos títulos buscan proteger la forma y el aspecto externo particular de un determinado artículo. El período de protección es similar al especificado para las patentes, de entre 15 y 20 años.

Los derechos de autor se definen como el instrumento para proteger materiales originales, incluyendo compilaciones de materiales publicados con anterioridad. En contraste con el procedimiento seguido para las patentes, la originalidad del material sujeto al derecho de autor no se determina antes de la expedición del reconocimiento del derecho de autor en cuestión. La duración de los derechos de autor es variable, pero generalmente se considera el tiempo de vida del autor más 50 años. Los derechos de autor por lo general no pueden ser exclusivos, el autor no puede prohibir a otros el uso de su trabajo, pero puede solicitar una compensación por el uso de su obra.
Principales acuerdos internacionales

Los acuerdos internacionales para la protección de los derechos de propiedad intelectual en el mundo, y en niveles regionales, han existido por más de un siglo. Los principales acuerdos mundiales, en correspondencia con lo que se concibe básicamente como propiedad intelectual, son el Convenio de París de 1883 para la Protección de la Propiedad Industrial; el Convenio de Berna de 1886 para la Protección de las Obras Literarias y Artísticas, que otorga protección a los derechos de autor; y el ADPIC, el cual entró en vigor a partir de 1995. Este acuerdo es el más general y pretende establecer mecanismos más eficientes para la protección internacional de los derechos de propiedad intelectual.

\section{El Convenio de París}

Este convenio establece mecanismos que tienen por objeto reglamentar el uso de "patentes, modelos de utilidad, dibujos, diseños o modelos industriales, marcas comerciales, marcas de servicios, nombres de comercios e indicaciones de procedencia o denominaciones de origen y poner límites a la competencia desleal". 9

El Convenio de París, aunque data del 20 de marzo de 1883, ha sido revisado en varias ocasiones. ${ }^{10}$ La más reciente, cuyo texto resultante es el que está vigente, se llevó a cabo el 14 de julio de 1967, en Estocolmo. Este convenio, con 107 países firmantes, que incluye a muchos subdesarrollados, tiene dos disposiciones principales: 1) "tratamiento nacional", es decir, igual tratamiento a nacionales y no nacionales (artículo 2, Texto de Estocolmo); y 2) la concesión de derechos de prioridad cuando se registre la misma patente o marca comer- 
cial en cualquier nación firmante dentro de un año (artículo 4). Aparte de esos dos principios, el convenio permite a los países firmantes flexibilidad en el establecimiento de leyes nacionales sobre patentes y marcas comerciales.

Los países que son exportadores de tecnología se benefician del sistema de "tratamiento nacional" del Convenio de París. Contrariamente, para importadores de tecnología este convenio neutraliza en efecto la opción de la selectividad para conceder patentes o marcas comerciales. ${ }^{11}$ Aun en presencia del Convenio, sin embargo, las naciones mantienen considerable libertad de acción para excluir productos de la protección y para emitir licencias obligatorias.

Esta flexibilidad dio la pauta para que el grupo de los países en desarrollo miembros del Convenio de París se propusiera reducir y debilitar los estándares internacionales de la protección de la propiedad industrial, lo que fue evitado con lo estipulado por el artículo 18 , el cual establece que las revisiones que se realicen al convenio serán únicamente con el fin de mejorar el sistema de protección de la propiedad industrial.

Estados Unidos fue la nación que estuvo al frente del grupo de los países desarrollados que defendieron el existente nivel de protección de propiedad industrial expresado en el Texto de Estocolmo. ${ }^{12}$ Además, fue uno de los más fervientes defensores del sistema, al grado que en temas importantes daba la impresión de que permanecía solo y casi aislado del resto de los demás países del grupo. ${ }^{13}$ Esta experiencia y el hecho de que el grupo de países en desarrollo tuviera un gran peso (por el número de éstos) en las negociaciones que se llevaban a cabo en el marco del Convenio de París, confirmaron la disposición de Estados Unidos para proponer la inclusión del tema de la protección de derechos de propiedad intelectual en las negociaciones del Acuerdo General sobre Aranceles y Comercio (GATT).

\section{El Convenio de Berna}

Este convenio, que otorga protección a las obras literarias y artísticas, incluye la protección de:

las producciones en el campo literario, científico $\mathrm{y}$ artístico, cualquiera que sea el modo o forma de expresión, tales como los libros, folletos y otros escritos; conferencias, discursos, sermones y otras obras de la misma naturaleza; obras dramáticas o dramático-musicales; obras coreográficas y funciones de pantomima; composiciones musicales con o sin palabras; obras cinematográficas a las cuales sean asimilados trabajos expresados por un proceso análogo al de la cinematografía; obras de dibujo, pintura, arquitectura, escultura, grabados y litografías; obras fotográficas a las cuales sean asimilados trabajos expresados por un proceso análogo a la fotografía; obras de arte aplicado; ilustraciones, mapas, planos, bosquejos y trabajos tridimensionales relativos a la geografía, topografía, arquitectura o ciencia. ${ }^{14}$

Al igual que el de París, también el Convenio de Berna ha sido modificado en varias ocasiones. ${ }^{15}$ La última revisión se llevó a cabo en París el 24 de julio de 1971, cuyo texto resultante es el que está vigente. Además, también como el Convenio de París, el Convenio de Berna está basado en el principio de igual tratamiento con respecto a la nacionalidad, pero va más allá en el establecimiento de estándares mínimos sustantivos.

En razón de que el Convenio de Berna establece estándares más específicos que el Convenio de París, las legislaciones nacionales de derechos de autor en diferentes países se pueden armonizar más ampliamente que la legislación de patentes. La protección de los derechos de autor bajo este convenio se extiende sin las formalidades de solicitud o de verificación. El período mínimo de protección es el del tiempo de vida del autor más 50 años. 
El Acuerdo sobre los Aspectos de los Derechos de Propiedad Intelectual Relacionados con el Comercio, incluyendo el comercio de mercancías falsificadas (ADPIC)

El ADPIC se empezó a negociar el 5 de febrero de 1987 a propuesta de los países desarrollados, concretamente Estados Unidos, los de la Comunidad Europea, Japón y Canadá. Esto como resultado del movimiento iniciado durante los setenta con el propósito de revisar los convenios de protección a la propiedad intelectual, con el argumento de que la falta de ejecución efectiva alentaba la piratería y la falsificación de la propiedad intelectual. Estos países también insistieron en que los convenios internacionales existentes hasta esa fecha deberían ser reforzados con mecanismos de disputas formales para asegurar la conformidad con el acuerdo. Sin embargo, la postura de los países en desarrollo era contraria a la mostrada por los desarrollados, lo que se reflejó en las negociaciones durante 1980 para acordar una revisión del Convenio de París. Los países en desarrollo buscaron, con base en un estudio elaborado por la Comisión de las Naciones Unidas para el Comercio y el Desarrollo (UNCTAD), introducir mecanismos que les permitieran mantener el uso de licencias obligatorias y disminuir el pago de la compensación a los autores de los trabajos protegidos, lo que facilitaría la transferencia de tecnología desde los países desarrollados.

Ambas posiciones se anularon y finalmente, después de tres reuniones celebradas entre 1980 y 1982, no se llegó a ningún acuerdo. El último intento se llevó a cabo en 1984 durante una reunión en Ginebra, pero las posiciones encontradas prevalecieron y el Convenio de París permanece aún como se acordó en Estocolmo en 1967.

El Convenio de Berna también fue criticado por su falta de mecanismos efectivos de ejecución de lo acordado y por la carencia de previsiones acerca de mecanismos formales de manejo de las disputas surgidas entre los países miembros con respecto al tema de la propiedad intelectual. No obstante lo anterior, este convenio no estuvo sujeto a revisión en ese tiempo, por lo que el texto vigente es el que resultó de la revisión de París, realizada el 24 de julio de 1971.

De esta manera, el movimiento impulsado por los países desarrollados para reforzar los convenios no tuvo los efectos deseados y, desde su perspectiva, sus intereses particulares en el terreno de la propiedad intelectual permanecieron expuestos a los daños que se les infringían en otros países. Además, a esto se sumaba el hecho de que consideraban que, bajo el entonces vigente marco de protección a los derechos de propiedad intelectual, los principales avances tecnológicos quedaban sin proteger.

Estados Unidos, muy particularmente, pensaba que sus intereses nacionales estaban amenazados bajo el prevaleciente sistema internacional de propiedad intelectual, lo que se reforzó con la presión de las principales industrias para usar las leyes internas con el fin de asegurar la protección en el extranjero. En 1985, la Asociación Internacional de la Propiedad Intelectual ${ }^{16}$ (IIPA) sugirió que el gobierno de Estados Unidos hiciera todo lo posible por establecer un clima de comercio adecuado en el cual la propiedad intelectual fuera protegida y respetada. Para responder a esta solicitud, y otras exigencias del mismo tipo, Estados Unidos necesitaba encontrar métodos alternativos para proteger sus intereses en el área de la propiedad intelectual.

Sin embargo, a Estados Unidos se le complicó la situación debido a que no era miembro firmante del Convenio de Berna, y cuando en 1984 se retiró de la Organización de las Naciones Unidas para la Educación, la Ciencia y la Cultura (UNESCo), aunque esto no lo privaba de participar en el Convenio Universal de los Derechos de Autor (UCC), se le prohibió asistir a reuniones en donde se negociaban asuntos importantes de este convenio, lo que disminuyó su capacidad de intervención con el objeto de reforzar la protección internacional de los derechos de autor. El resultado final de todo esto fue que Estados Unidos se empezó a pre- 
ocupar por la pérdida potencial de su influencia política que la situación le podría ocasionar en el sistema internacional de la propiedad intelectual.

El debate que se suscitó, desde finales de los setenta y hasta mediados de los ochenta, sobre el sistema internacional de propiedad intelectual dejó en claro las diferentes concepciones de la propiedad intelectual como un interés nacional. De este modo, "desde la perspectiva de los países desarrollados, la propiedad intelectual es un derecho privado que debería ser protegido como cualquier otra propiedad tangible. Desde la perspectiva de los países en desarrollo, la propiedad intelectual es un bien público que debería ser usado para promover el desarrollo económico". ${ }^{17}$

Estas posiciones se reflejaron en los intentos desplegados para la revisión de los acuerdos en la materia y la falta de consenso sobre las medidas pertinentes a aplicar para la solución de las diferencias.

\section{La posición de Estados Unidos fuera del GATT}

El debate sobre el sistema internacional de la protección a los derechos de propiedad intelectual también dio oportunidad a Estados Unidos de utilizar sus leyes nacionales y las negociaciones bilaterales como una alternativa a las infructuosas negociaciones multilaterales, en correspondencia a su posición como un país líder en la exportación de tecnología y las presiones de la industria nacional para buscar la protección de la propiedad intelectual en el extranjero, lo que definió su postura con respecto a la protección internacional de la propiedad intelectual. Esto se reflejó en la Ley de Comercio de 1984, la cual otorga a la Oficina del Representante Comercial de Estados Unidos (USTR) más autoridad para tratar asuntos de propiedad intelectual relacionada con el comercio y para usar la facultad de permitir o negar el acceso de las mercancías al mercado de Estados Unidos, como medida para presionar a otros países por un mejoramiento de la protección a los derechos de propiedad intelectual.

La Ley de Comercio de 1984 también permitió que la sección 301 de la respectiva Ley de 1974 tuviera una aplicación explícita en problemas relacionados con la propiedad intelectual, lo que "posibilita al presidente buscar la eliminación de prácticas comerciales 'injustificables o irrazonables' a través de la aplicación de medidas que incluyen las represalias por medio de la restricción de importaciones al mercado de Estados Unidos". ${ }^{18}$ Esto tuvo otro efecto colateral: dio elementos para disuadir a otros países a establecer acuerdos bilaterales con éste, de modo que se reforzara la protección de la propiedad intelectual en ellos.

El Sistema Generalizado de Preferencias (SGP) también se utilizó por parte de Estados Unidos como un arma para presionar a otros países a tomar medidas más estrictas de protección a la propiedad intelectual, ya que en la evaluación para otorgarles la calificación necesaria para ingresar al programa del SGP, se tomaban en cuenta los indicadores de tal protección. Así, los países que, a criterio de Estados Unidos, no cumplieran con las expectativas relacionadas con la protección de la propiedad intelectual en su territorio, se veían excluidos de los beneficios que proporcionaba la entrada al SGP.

La sección 301 de la Ley de Comercio de 1974, reforzada por la de 1984, y el sGP fueron algunas de las medidas más importantes aplicadas con el objeto de reforzar la protección de los derechos de propiedad intelectual antes del inicio de las negociaciones de la Ronda Uruguay del Gaтт. ${ }^{19}$ Sin embargo, una vez que se iniciaron las mencionadas negociaciones, ${ }^{20}$ Estados Unidos buscó aplicar medidas más fuertes para mejorar la protección internacional de la propiedad intelectual. Éste fue el objetivo de la inclusión de la provisión llamada "Súper 301" en la Ley General de Comercio y Competitividad de 1988, cuyo fin es el de proveer una estrategia más completa para la protección de los derechos de propiedad inte- 
lectual. La Ley faculta a la USTR a identificar a los países que no brindan una protección adecuada a la propiedad intelectual y ponerlos ya sea en la lista de observación prioritaria o cuando menos en la lista de observación, de acuerdo con los problemas detectados en ellos para aplicar tal protección. El uso de la "Súper 301” proporcionó a Estados Unidos una fuerte influencia en su relación con países que no habían actualizado sus prácticas en la protección de los derechos de propiedad intelectual, de conformidad con los lineamientos sobre estándares de protección propuestos en la Ronda Uruguay del GATT, aun cuando estos estándares no hubieran sido todavía acordados formalmente.

A pesar de que con la aplicación de los tres mecanismos mencionados Estados Unidos logró aumentar la protección en la materia para ciertas industrias en algunos países en particular, Washington "mantuvo su posición de que la protección internacional efectiva podría ser mejor lograda a través de las negociaciones multilaterales". ${ }^{21}$

\section{La posición de Estados Unidos dentro del GATT}

Tanto para Estados Unidos como para otros países desarrollados, el GATT proporcionaba el marco más viable para lograr un acuerdo multilateral efectivo que limitara el comercio de bienes falsificados, que había experimentado un considerable crecimiento hacia finales de los setenta. Esta convicción y la presión de las poderosas industrias afectadas de Estados Unidos, condujeron a que éste encabezara un esfuerzo en el seno del GATT, con el objetivo de establecer mecanismos para regular el comercio de mercancías falsificadas. Esto en razón de que la protección inadecuada de las marcas comerciales, y la comercialización de los bienes falsificados que esta situación trae consigo, es probablemente la violación más importante a los derechos de propiedad intelectual. ${ }^{22}$

Así, durante la Ronda Tokio del GATT, las delegaciones de Estados Unidos y la Comuni- dad Europea trabajaron en la negociación de la propuesta de un proyecto de código sobre la materia. A pesar de que no se logró ningún arreglo al respecto hasta antes del fin de la Ronda, el 31 de julio de 1979, Estados Unidos y la Comunidad Europea llegaron a una resolución y presentaron una propuesta de proyecto de código denominada "Acuerdo sobre Medidas para Desalentar la Importación de Bienes Falsificados". ${ }^{23}$

Aún después de terminada la Ronda Tokio, Estados Unidos y la Comunidad Europea unieron esfuerzos para procurar mayores apoyos de otros países desarrollados para el proyecto de código propuesto. De esta manera, como resultado de las reuniones informales que entre 1980 y 1981 sostuvieron representantes de Estados Unidos y la Comunidad Europea con sus contrapartes de Japón, Canadá y Suiza, en 1982 se sometió un nuevo texto del proyecto de código con el apoyo adicional de Japón y Canadá. Este movimiento, sin embargo, no tuvo éxito en conseguir un apoyo más amplio hasta antes de la Reunión Ministerial de 1982.

Durante la Reunión Ministerial de 1982, Estados Unidos continuó con sus esfuerzos para incluir en las negociaciones el tema de los bienes falsificados. Estos esfuerzos para incluir el código contra la falsificación en la agenda de trabajo del GATT enfrentaron la oposición de muchos países en desarrollo. Entre ellos, "India y Brasil argumentaron que la jurisdicción del GATT estaba limitada a bienes tangibles y, por lo tanto, el GATT carecía de competencia legal para dirigir una disputa dentro del área de la propiedad intelectual". ${ }^{24}$

La postura era que el problema debía ser tratado en el marco exclusivo de la jurisdicción de la ompr. A pesar de esto, la Declaración Ministerial de 1982 estableció que debería realizarse un examen más completo del caso, para lo cual recomendó que el director general del GATT sostuviera algunas consultas con el director general de la oMPI, a fin de clarificar los aspectos legales e institucionales involucrados. 
Durante la $40^{a}$ Sesión de las Partes Contratantes, en 1984, se acordó continuar con el programa de trabajo de 1982 en lo que se refería a los bienes falsificados. Además, contra la postura de algunas delegaciones, el Consejo del GATT acordó designar a un grupo de expertos para estudiar los efectos de la falsificación de bienes con reconocimiento de marca comercial en el comercio internacional. El grupo de expertos consignó: a) la capacidad de las leyes nacionales para atacar el problema de la falsificación; b) la autoridad del GATT para actuar en el área; c) los métodos al alcance del GATT, y d) el efecto potencial de las medidas contra la falsificación en el comercio internacional.

El grupo de expertos concluyó, además, que en razón de que varios temas seguían sin resolverse, el Consejo del GATT debería determinar si las negociaciones multilaterales en el marco del GATT podrían dirigir exitosamente los temas en disputa. Así, a pesar de que durante la $40^{a}$ Sesión no hubo progresos significativos sobre el tema del comercio de los bienes falsificados, el Consejo del GATT decidió designar a un Comité de Preparación para que consignara los temas a tratar en una nueva ronda de negociaciones multilaterales.

El amplio mandato que se le otorgó al Comité de Preparación condujo a la inclusión del tema de la protección de derechos de propiedad intelectual en las negociaciones de la Ronda Uruguay del GATT. Estados Unidos, aprovechando este amplio mandato, sometió una propuesta para incluir todos los derechos de propiedad intelectual, ${ }^{25}$ en lugar de sólo los bienes falsificados. ${ }^{26}$ Esta propuesta reflejó la posición de Estados Unidos de que el GaTT era el marco adecuado para buscar el refuerzo de la protección internacional de los derechos de propiedad intelectual. Además, renovó el debate sobre si el tema de la propiedad intelectual estaba dentro de la jurisdicción del GATT. Varios países en desarrollo argumentaron que el problema de los bienes falsificados no sólo estaba más allá de la autoridad del GATT, sino que el GATT no podría extenderse para tratar asuntos que tuvieran que ver con derechos de autor y patentes, porque esas protecciones cubrían objetos intangibles.

Aun así, los ministros del GATT recibieron tres propuestas en total. Una encabezada por las delegaciones de Suiza y Colombia, que representaba la postura de cuarenta delegaciones, de países desarrollados y en desarrollo, que en sus recomendaciones incluía el tema de la protección a los derechos de propiedad intelectual y el de servicios. Las otras dos propuestas eran de Brasil y Argentina. Brasil, en nombre de otros nueve países, sometió a discusión su propuesta en la que firmemente se opuso a la inclusión del tema de la protección de derechos de propiedad intelectual y el de servicios. Argentina, por su parte, consideraba la inclusión de los servicios, pero excluía los derechos de propiedad intelectual. A final de cuentas, la propuesta presentada por las delegaciones de Suiza y Colombia sirvió como base para la Declaración Ministerial de 1986.

\section{El proceso de negociación del ADPIC}

El 20 de septiembre de 1986, en la Declaración Ministerial para las futuras negociaciones sobre el comercio de bienes, se incluyó el tema correspondiente al ADPIC. Los objetivos de la negociación para el grupo se definieron de la siguiente manera:

Con el fin de reducir las distorsiones e impedimentos al comercio internacional, tomando en cuenta la necesidad de promover la adecuada y efectiva protección de los derechos de propiedad intelectual y asegurar que las medidas y procedimientos para reforzar los derechos de propiedad intelectual no se conviertan en sí mismas en barreras al comercio legítimo, las negociaciones deberán intentar esclarecer las provisiones del GATT y elaborar nuevas reglas y disciplinas apropiadas.

Las negociaciones deberán intentar desarrollar un marco multilateral de principios, reglas y disciplinas que versen sobre el comercio internacional de bienes falsificados, tomando en cuenta el trabajo ya emprendido en el GATT. 
Esas negociaciones deberán ser sin perjuicio de otras iniciativas complementarias que puedan ser tomadas en la Organización Mundial de la Propiedad Intelectual y en cualquier otra parte para tratar con esas cuestiones. ${ }^{27}$

El 19 de octubre de 1987, durante la primera fase de las negociaciones, la USTR presentó su propuesta. En ella, Estados Unidos planteó ciertas normas de referencia con base en las cuales los demás países pudieran crear sus propias leyes nacionales para proteger los derechos de propiedad intelectual, tomando en cuenta los convenios internacionales y las leyes nacionales existentes. Así, los países firmantes se comprometerían a adoptar leyes nuevas y adaptar las ya existentes para proporcionar una protección que fuera consistente con las normas previstas en el acuerdo. Esto serviría, además, como incentivo para que otros países se unieran al acuerdo. ${ }^{28}$

Las delegaciones de Suiza, Japón y la Comunidad Europea también presentaron sus propuestas durante la primera fase de negociaciones. La propuesta de Suiza llamó la atención sobre la necesidad de perfeccionar la ejecución de la protección a la propiedad intelectual. La propuesta de Japón básicamente fue similar a la de Estados Unidos. La propuesta de la Comunidad Europea contempló que el ADPIC debería cubrir nuevos tipos de propiedad intelectual, así como la aplicación de principios básicos del GATT, como el de tratamiento nacional, el de no-discriminación y el de transparencia. ${ }^{29}$

Durante la segunda fase de las negociaciones muchos países desarrollados reportaron al GATT que las operaciones de sus compañías estaban amenazadas no sólo por las conocidas prácticas de falsificación, sino también por problemas que tenían que ver más generalmente con una inadecuada protección de la propiedad intelectual, justificando así la demanda de los países desarrollados por un tratamiento con mayor amplitud del tema, con la intención de incorporar una concepción más amplia de la propiedad intelectual.
También los países en desarrollo presentaron sus propuestas, las cuales estaban más bien fundamentadas en la preocupación por el acceso a la tecnología moderna, lo que bien podría dificultarse por la sobreprotección de los derechos de propiedad intelectual. Por ejemplo, México propuso que "el objetivo de la negociación con respecto al mejoramiento de los derechos de propiedad intelectual no debería convertirse en una barrera al acceso de los países en desarrollo a las tecnologías producidas en los países desarrollados". ${ }^{30}$ Los primeros argumentaron también que sus necesidades de desarrollo eran iguales o más importantes que los intereses de los propietarios de los derechos de propiedad intelectual. Así, Brasil estableció que

las discusiones en este Grupo de Negociación parecen estar mucho más concentradas en el lado de los propietarios de los derechos de propiedad intelectual. Si vamos a tener un análisis realista y balanceado de las implicaciones del tema en relación con la promoción del crecimiento y el desarrollo, es fundamental dar la debida consideración a los aspectos relevantes para los usuarios de los derechos de propiedad intelectual. ${ }^{31}$

Durante la revisión a mitad del camino, en diciembre de 1988 en Montreal, con respecto al tema de la propiedad intelectual, se buscó consenso sobre el marco de un acuerdo y un último empeño para negociar estándares mínimos sustantivos. Aunque se estuvo cerca de lograr un acuerdo, la posición de algunos países en desarrollo, sobre todo de Brasil y la India, evitó el logro de este objetivo en Montreal. ${ }^{32}$ Sin embargo, el acuerdo sobre el marco del ADPIC fue alcanzado en abril de 1989. En este acuerdo se convocó a futuras negociaciones para tratar los estándares con respecto al alcance y uso de los derechos de propiedad intelectual y los medios para hacerlos respetar. Se acordó, además, que dichas negociaciones deberían conducir a una relación de mutuo soporte entre el GATT y la OMPI, así como con otras organizaciones internacionales relevantes en el tema. ${ }^{33}$ 
El grupo de negociación del ADPIC se reunió dos veces en julio de 1989. La primera se enfocó en la aplicabilidad de los principios básicos del GATT al tema de la propiedad intelectual. Durante la segunda reunión las discusiones se centraron en las normas y principios con respecto al alcance y aplicación de los derechos de propiedad intelectual. Las propuestas de Australia, los países nórdicos y Suiza eran similares a la posición de Estados Unidos en relación con la materia a proteger, los criterios para los beneficios de tal protección y el alcance de ésta.

La posición de la India se distinguió por el hecho de expresar la postura de que sólo las prácticas que distorsionaran el comercio internacional deberían estar sujetas a negociación. La India también planteó la necesidad de tratamiento preferente en las áreas de patentes y marcas comerciales para los países en desarrollo y de flexibilidad para adaptar sus leyes nacionales a las necesidades de desarrollo y de interés público de éstos.

De octubre a diciembre de 1989 se presentaron propuestas por parte de Corea, Hong Kong, Austria, Brasil y Australia. Corea y Brasil propusieron que deberían permitirse las licencias obligatorias de patentes, mientras que Hong Kong y Austria plantearon medidas más restrictivas, en el sentido de que tales licencias sólo deberían otorgarse para satisfacer al mercado interno, no ser exclusivas y estar sujetas a una compensación apropiada. Australia, por su parte, presentó una propuesta que consideraba la inclusión de seis principios generales para lograr el refuerzo de la protección a los derechos de propiedad intelectual. Estos principios tenían que ver con la aplicación de: a) procedimientos imparciales y equitativos; b) medidas provisionales; c) remedios civiles; d) sanciones penales; e) detención de mercancías; f) salvaguardas. ${ }^{34}$

Hacia finales de 1989 la negociación del ADPIC produjo muchas propuestas, pero realmente pocos resultados sustantivos. El principal consenso alcanzado fue de que a los países menos desarrollados se les debería permitir un tiempo adicional para realizar las modificaciones necesarias con el fin de ajustarse al texto final del acuerdo de propiedad intelectual.

Al inicio de 1990 se presentaron cinco borradores a las negociaciones del ADPIC. Cuatro de éstos fueron propuestos por países desarrollados: Estados Unidos, los miembros de la Comunidad Europea, Suiza y Japón, en tanto que el quinto texto lo presentó un grupo de países en desarrollo (Argentina, Brasil, Chile, China, Colombia, Cuba, Egipto, Nigeria, Perú, Tanzania y Uruguay). La diferencia más general entre estos borradores era que mientras los países desarrollados planteaban la negociación de un acuerdo comprensivo sobre la materia, los países en desarrollo trataban la propiedad intelectual no como un derecho de propiedad, sino más bien como un instrumento de política pública.

Sin embargo, en cuestiones más específicas empezaron a aparecer diferencias entre los mismos países desarrollados. Por ejemplo, con respecto a la protección de patentes, el borrador de Estados Unidos no contempló ninguna excepción para los rubros objeto de protección por patentes, en tanto que el borrador de la Comunidad Europea y el de los países en desarrollo excluyeron el reconocimiento de patentes para inventos que fueran contrarios al bien público y a la salud. Además, Estados Unidos y la Comunidad Europea tuvieron diferencias con respecto a la protección de las indicaciones geográficas y denominaciones de origen, pues mientras Estados Unidos consideraba la protección sólo para denominaciones de origen no genéricas, la Comunidad Europea definió explícitamente el uso de las indicaciones geográficas e incluyó un artículo sobre las medidas de protección que un país puede aplicar para prevenir que las indicaciones geográficas tiendan a convertirse en genéricas.

Así, aunque se registraban avances, persistieron las mencionadas diferencias, tanto en lo general como en lo particular, de modo que hacia finales de 1990 se seguía considerando que "los temas más sensitivos políticamente 
continúan sobresaliendo [...] 1) la aplicación del ADPIC en el marco del GATT y 2) el refuerzo de los procedimientos de resolución de disputas usados para resolver las disputas sobre propiedad intelectual". ${ }^{35}$

Después de un año más de negociaciones en el marco del GATT, sin llegar a un acuerdo definitivo, el 20 de diciembre de 1991, el director general del GATT, Arthur Dunkel, presentó un texto ${ }^{36}$ que proporcionó una resolución a temas aún no decididos por los negociadores. En dicho texto se resolvieron algunas de las cuestiones más problemáticas a las que se enfrentaban dichos negociadores. Por ejemplo, Estados Unidos obtuvo respuesta a su demanda de no tener que respetar los derechos morales de los autores, ya que en el artículo 9 se especificó que "las partes no tendrán derechos u obligaciones bajo este Acuerdo, con respecto a los derechos conferidos en el artículo 6bis de ese Convenio [de Berna] o de los derechos derivados de éste". ${ }^{37} \mathrm{El}$ artículo $6 b i s$ del Convenio de Berna, en su versión vigente, establece que

independientemente de los derechos económicos del autor, y aún después de la transferencia de dichos derechos, el autor tendrá el derecho de reclamar la autoría de la obra y objetar cualquier distorsión, mutilación u otra modificación o acción despreciativa en relación con dicho trabajo, que fuera perjudicial a su honor o reputación. ${ }^{38}$

La respuesta, pues, fue consistente con la posición de Estados Unidos de que los derechos morales no se deberían sujetar al mecanismo de manejo de disputas previsto en el ADPIC. Además, se resolvió la diferencia entre Estados Unidos y Japón con respecto a los derechos de alquiler, al especificar que los autores tienen el derecho de "autorizar o prohibir el alquiler comercial al público de los originales o copias de sus obras amparadas por el derecho de autor" (artículo 11). ${ }^{39}$ Esta disposición reconoció el sistema de alquiler de grabaciones sonoras existente en Japón.

La Comunidad Europea obtuvo el mejoramiento de la protección para las denomina- ciones de origen al considerarse en el Acuerdo, artículo 23, que las indicaciones geográficas para vinos y bebidas espirituosas deberían contar con protección adicional. ${ }^{40}$ Aparte de esas cuestiones un tanto particulares, se estableció una cobertura más amplia para el sistema internacional de protección a los derechos de propiedad intelectual.

Sin embargo, los países en desarrollo y la Comunidad Europea, contra la postura de la mayoría de los países desarrollados, también lograron que los temas sobre plantas y microbiología quedaran excluidos de la protección por patentes, tal como se considera en el artículo 27.41 Consiguieron, además, períodos de transición sustancialmente más largos que los estipulados para los países desarrollados, ${ }^{42}$ de manera que para éstos la aplicación del Acuerdo sería al año siguiente de que entrara en vigor, es decir, a partir de 1996. En cambio, para los países en desarrollo, se concedió un período adicional de cuatro años, y para los países menos desarrollados y para sectores de importancia estratégica en los países en desarrollo se concedió un tiempo adicional de cinco años (artículos 65 y 66). ${ }^{43}$ Esto sin menoscabo de lo previsto en los artículos 3,4 y 5 del Acuerdo, que se refieren al tratamiento nacional para no nacionales, al trato de nación más favorecida y a la relación de este Acuerdo con otros acuerdos multilaterales, respectivamente, los cuales se empezarían a aplicar al año de entrada en vigor del ADPIC.

Con respecto al refuerzo de los procedimientos para asegurar la protección internacional de los derechos de propiedad intelectual, se acordó que el asegurar la creación de fuertes medidas de apuntalamiento en el ámbito nacional era una prioridad, como se estableció en los textos presentados por Estados Unidos, la Comunidad Europea y Suiza. Esto con base en que tal prioridad fue uno de los principales componentes que empujaron a los países desarrollados a proponer la negociación de un acuerdo multilateral sobre los aspectos de los derechos de propiedad intelectual relacionados con el comercio, cuyo resultado fue el ADPIC. Los países en desarrollo no estuvieron 
tan preocupados con este asunto, pues pedían que se consideraran ciertas tolerancias en reconocimiento de los límites financieros y administrativos propios de su infraestructura en el área de la propiedad intelectual.

El enfoque anterior difirió sustancialmente del que tenían los países desarrollados, los cuales pidieron el refuerzo de los procedimientos administrativos, civiles y penales, así como remedios a los daños y perjuicios, a través de amonestación o multa, y de la destrucción o disposición de las mercancías que causen dichos daños y perjuicios. Además, previeron amplias medidas provisionales y fronterizas. Sin embargo, también existían diferencias entre ellos, pues mientras Estados Unidos quería limitar los remedios disponibles contra el gobierno para el pago o la compensación total del propietario del derecho, la Comunidad Europea propuso la indemnización y el derecho de demandar a las autoridades que erróneamente retengan mercancías.

Había también diferencias con respecto a las áreas apropiadas para la aplicación de las sanciones penales. Mientras Estados Unidos se limitaba a proponer las sanciones sólo para los daños premeditados, a escala comercial, a las marcas comerciales y los derechos de autor, Suiza las propuso para cualquier tipo de daños premeditados a una escala comercial.

En el texto del ADPIC se contempla que los procedimientos de observancia de los derechos de propiedad intelectual deben permitir la adopción de medidas eficaces contra cualquier acción infractora sobre estos derechos y que los recursos disponibles deben ser ágiles para prevenir las infracciones y deben constituir un medio de disuasión de nuevas infracciones. Asimismo, se estipula que esos procedimientos deben aplicarse de forma que se evite la creación de obstáculos al comercio legítimo y deben prever salvaguardas contra su abuso. Además, contiene disposiciones sobre procedimientos y recursos civiles y administrativos, medidas provisionales, prescripciones especiales relacionadas con las medidas en frontera, y procedimientos penales en los que se especifican con cierto detalle los procedimientos y recursos que deben existir para que los titulares de los derechos de propiedad intelectual puedan hacerlos respetar de manera efectiva.

\section{Conclusiones}

La protección internacional de los derechos de propiedad intelectual, no obstante que se ha venido promoviendo desde hace más de un siglo, había avanzado de manera incierta e intermitente. Esto a pesar de que los dos convenios principales sobre el tema, el de $\mathrm{Pa}-$ rís y el de Berna, especificaban ya desde su entrada en vigor los principios y normas elementales que deberían tomarse en cuenta para la apropiada protección internacional de los derechos de propiedad intelectual. Así, el principio de trato nacional a no nacionales y el de trato de nación más favorecida, se hacen presentes en las disposiciones contenidas en los dos convenios mencionados. De igual manera, se establecen en éstos las normas mínimas que han de observar los países que se sujeten a lo dispuesto sobre la materia, ya sea por el Convenio de París o por el de Berna.

Sin embargo, la acusación que se les hizo a estos dos convenios de que no tenían la suficiente fortaleza en la aplicación de los principios y las normas, dio sustento a la propuesta por parte de los países desarrollados de la revisión de los mecanismos que permiten asegurar el cumplimiento de lo acordado. De este modo, se inició desde finales de los setenta el debate sobre la pertinencia de la inclusión del tema de la protección de los derechos de propiedad intelectual en el marco del GATT, con el objeto de reforzar los mecanismos considerados para hacer valer tales derechos.

Después de casi una década de negociaciones, de la cual la mitad se llevó a cabo en el marco del GATT, finalmente fue aprobado el ADPIC. En este acuerdo se incorporan las provisiones principales del Convenio de París y del de Berna en sus versiones más recientes. Con excepción de las disposiciones del Convenio de 
Berna sobre los derechos morales, todas las demás obligaciones sustantivas de esos convenios se incorporan por referencia al ADPIC. Así, el ADPIC refrenda lo dispuesto por estos convenios, con la excepción mencionada, pero además establece un conjunto de disposiciones que hacen referencia a los procedimientos y recursos que permiten la observancia internacional de los derechos de propiedad intelectual.

Con la incorporación de los principios y normas fundamentales de los principales convenios sobre propiedad intelectual en el ADPIC y el fortalecimiento de las medidas para reforzar la aplicación de las reglas estipuladas en éste, al mismo tiempo que las diferencias surgidas entre las partes se sujetan a los mecanismos de solución de diferencias de la omc, la protección internacional de los derechos de propiedad intelectual ha experimentado cambios que, aunque para algunos podrían no ser los indicados, han permitido avanzar en aspectos sustanciales del tema. De este modo, el ADPIC es hasta la fecha el acuerdo global, multilateral, más completo sobre propiedad intelectual.

Con la entrada en vigor del ADPIC se logró incorporar algunos aspectos que los convenios existentes con anterioridad no consideraban, con lo que se propició que éste alcanzara una cobertura más amplia y precisa con vistas al mejoramiento de la protección internacional de los derechos de propiedad intelectual. Además, se pusieron en operación una serie de mecanismos que permiten asegurar en gran medida el cumplimiento de las obligaciones acordadas. De esta manera, no sólo se enriquece el contenido de las disposiciones sino que se especifican los procedimientos y medidas a tomar en situaciones muy concretas, con lo que se logra reforzar sustancialmente la protección internacional d e los derechos de propiedad intelectual.

Las normas y principios generales, como la inclusión del tratamiento de la propiedad intelectual en el marco del GATT y las cláusulas sobre tratamiento nacional y nación más favorecida, reconocidos por todos los países miem- bros, le dan una nueva dimensión al tema. De manera que, en la transformación del GATT en la omc, los alcances de éste son más amplios, al incluir no sólo el comercio de bienes, de servicios y las inversiones, sino también el intercambio de ideas, como resultado de la protección de la propiedad intelectual en el marco de la omc.

Las reglas más claras con respecto a las prescripciones para la debida observancia de las disposiciones del ADPIC y los procedimientos administrativos para la aplicación de medidas estándares con objeto de facilitar la solución de controversias, hacen que se regule de manera más uniforme. Así, las decisiones que se tomen estarán más apegadas a las normas establecidas que guían el comportamiento de los países en cuanto a la protección internacional de los derechos de propiedad intelectual.

Así, el reforzamiento que experimentó la protección internacional de los derechos de propiedad intelectual, se fundamenta principalmente en el esclarecimiento de las normas y principios subyacentes en el tema y el establecimiento o mejoramiento de las reglas y procedimientos que lleven a un país a proporcionar a los demás países el trato previsto en el ADPIC. Con esto es posible hablar de la formación de un régimen internacional sobre protección de derechos de propiedad intelectual, el cual estaría representado por este Acuerdo.

Estados Unidos, si bien siguió usando medidas unilaterales a fin de reforzar la protección de esos derechos, cambió de estrategia y utilizó principalmente la negociación multilateral como el mecanismo más efectivo para lograr el aumento del nivel de la protección de los derechos de propiedad intelectual en el mundo. Es decir, dejó de usar la amenaza de sanciones o represalias comerciales (como su principal arma de presión) y privilegió la negociación con argumentos, con los que poco a poco fue ganando adeptos, entre los países en vías de desarrollo y entre los desarrollados, que compartieran sus propuestas. 
Así logró lo que no había podido hacer por la fuerza o con amenazas.

De esta manera, las variables más relevantes para la formación y entrada en vigor del mencionado régimen internacional, fueron las consideradas por los teóricos de regímenes internacionales: la negociación basada en argumentos, el mejoramiento de los canales de comunicación que posibilitara el entendimiento común de los problemas y el conocimiento del tema propiciado por una mayor difusión de las ideas acerca del tema, entre otras.

\section{Notas}

1 Las mercancías falsificadas se definen fundamentalmente como bienes que implican una copia servil de marcas comerciales o de fábrica. Las mercancías piratas, por otra parte, se definen como mercancías que violan un derecho de reproducción protegido por el derecho de autor.

2 Bernard M. Hoekman, "New Issues in the Uruguay Round and Beyond", The Economic Journal, 103, noviembre de 1993, p. 153.

3 Terence P. Stewart, "Trade-Related Aspects of Intellectual Property Rights", en The GATT Uruguay Round: A Negotiating History, (1986-1992), volume II: Commentary, Terence P. Stewart (ed.), Kluwer Law and Taxation Publishers, Deventer, The Netherlands, 1993, p. 2245.

4 Ibid., p. 2256. También Lynne Saylor y John Beton, "Why the TRIPs Agreement?", en Intellectual Property \& International Trade. A Guide to the Uruguay Round TRIPS Agreement, International Chamber of Commerce, Publication 552, ICC Publishing, S.A., París, 1996, p. 13.

5 También conocido como TRIPS, por sus siglas en inglés (Trade Related Aspects of Intellectual Property Rights).

6 El ADPIC constituye el anexo 1C del Acuerdo de Marrakech por el que se establece la Organización Mundial del Comercio (OMC), también denominado el Acuerdo de la omc, el cual fue concertado el 15 de abril de 1994 y entró en vigor el 1 de enero de 1995. Sin embargo, para la aplicación efectiva del ADPIC se establece un período de gracia de un año para cualquier país miembro, cinco años para los países en desarrollo y de diez años para los menos desarrollados.

7 Éste se entiende como los principios, normas, reglas y procedimientos de toma de decisiones alrededor de los cuales las expectativas de los actores convergen en un área de tema dada de relaciones internacionales. Para una profundización sobre el concepto, véanse: Stephen D. Krasner (ed.), International Regimes, Cornell University Press, Ithaca, 1983; Andreas Hasenclever, Peter Mayer y Volker Rittberger, Theories of International Regimes, Cambridge University Press, Cambridge, Reino Unido, 2000.
8 Terence P. Stewart (ed.), op. cit., volume II: Commentary, p. 2246

9 United International Bureaux for the Protection of Intellectual Property, "Paris Convention for the Protection of Industrial Property", en op. cit., volume III: Documents, Terence P. Stewart (ed.), p. 937.

10 La primera fue realizada en Bruselas el 14 de diciembre de 1900; la segunda se hizo en Washington el 2 de junio de 1911; la tercera, en La Haya el 6 de noviembre de 1925; la cuarta se realizó en Londres el 2 de junio de 1934; la quinta fue hecha el 31 de octubre de 1958 en Lisboa, y la última se llevó a cabo el 14 de julio de 1967 en Estocolmo.

11 William Lesser, "An Overview on Intellectual Property Systems", en Strengthening Protection on Intellectual Property in Developing Countries: A Survey of the Literature, Wolfgang E. Siebeck (ed.), The World Bank, Washington, D.C., 1990, p. 11.

12 Ulrich Joos y Rainer Moufang, "Report on the Second Ringberg-Symposium", en GATT or WIPO? New Ways in the International Protection of Intellectual Property, Symposium at Ringberg Castle, 13-16 de julio, 1988, Friedrich-Karl Beier y Gerhard Schricker (eds.), vcH Publishers, New York, 1989, p. 21.

13 Hans Peter Kunz-Hallstein, "The U.S. Proposal for a GATT-Agreement on Intellectual Property and the Paris Convention for the Protection of Industrial Property", en op. cit., Friedrich-Karl Beier y Gerhard Schricker (eds.), p. 77.

14 Terence P. Stewart, "Berne Convention for the Protection of Literary and Artistic Works", en op. cit., Terence P. Stewart (ed.), volume III: Documents, p. 903.

15 La primera de ellas se efectuó, con el fin de completarla, en París el 4 de mayo de 1896; la segunda revisión se llevó a cabo en Berlín el 13 de noviembre de 1908; la tercera también fue realizada para completarla el 20 de marzo de 1914 en Berna; la cuarta revisión se realizó en Roma el 2 de junio de 1928; la quinta se llevó a efecto el 26 de junio de 1948 en Bruselas; la sexta, en Estocolmo el 14 de julio de 1967; la última revisión se llevó a cabo en París el 24 de julio de 1971.

16 La IIPA está compuesta de siete asociaciones comerciales: la Asociación Americana de la Industria Disquera; la Asociación Americana de Editores; la Asociación de la Industria de Software de Cómputo y Servicios; la Asociación Americana de Comerciantes de Películas; la Asociación de Fabricantes de Equipo de Cómputo y Negocios, y la Asociación Nacional de Editores de Música. Por supuesto, todas de Estados Unidos.

17 Terence P. Stewart (ed.) “Trade-Related Aspects...”, en op. cit., vol. II: Commentary, p. 2255.

18 Ibid., p. 2256.

19 VanGrasstek Communications, "Trade-Related Intellectual Property Rights: United States Trade Policy, Developing Countries and the Uruguay Round", en Uruguay Round: Furthers Papers on Selected Issues, United Nations (UNCTAD), New York, 1990, p. 111.

20 El 20 de septiembre de 1986 los ministros adoptaron la Declaración Ministerial de la Ronda Uruguay en la que uno de los temas a incluir eran los Aspectos de los 
Derechos de Propiedad Intelectual Relacionados con el Comercio (ADPIC).

21 Terence P. Stewart (ed.) “Trade-Related Aspects...”, en op. cit., vol. II: Commentary, p. 2259.

22 United Nations, Intellectual Property Rights and Foreign Direct Investment, Nueva York, 1993, p. 14.

23 Terence P. Stewart (ed.) "Trade-Related Aspects ...", en op. cit., vol. II: Commentary, p. 2260.

24 Ibid., p. 2261.

25 La propuesta de Estados Unidos consideró la protección para patentes, marcas comerciales, derechos de autor, trabajos ocultos y secretos comerciales.

26 Hans Peter Kunz-Hallstein, "The U.S. Proposal for a GATT-Agreement on Intellectual Property and the Paris Convention...", en op. cit ., Friedrich-Karl Beier y Gerhard Schricker (eds.), p. 78.

27 "Trade-Related Aspects on Intellectual Property Rights, Including Trade in Counterfeit Goods. Negotiating Plan", en op. cit., Terence P. Stewart (ed.), volume III: Documents, p. 22.

28 Office of the United States Trade Representative, "Suggestion by the United States for Achieving the Negotiating Objective, GATT-Doc. MTN/NG11/w/14 (20 de octubre de 1987)", en op. cit., Friedrich-Karl Beier y Gerhard Schricker (eds.), pp. 179-186.

29 Terence P. Stewart (ed.) "Trade-Related Aspects...", en op. cit., vol. II: Commentary, p. 2267. También European Community, "Guidelines Proposed by the European Community for the Negotiations on Trade-Related Aspects of Intellectual Property Rights, GATT-Doc. MTN.GNG/NG11/w/16 (20 de noviembre de 1987)", en op. cit., Friedrich-Karl Beier y Gerhard Schricker (eds.), pp. 203-210.

30 Statement Made by the Delegation of Mexico at the Meeting of 17, 18 and 21 October 1988, apud Terence P. Stewart (ed.), "Trade-Related Aspects ...", en op. cit., vol. II: Commentary, p. 2267.

31 Submission from Brazil, GATT Doc. No. MTN.GNG/NG11 h/ 30 (October 31, 1988), apud Terence P. Stewart (ed.) “Trade-Related Aspects ...", en op. cit., vol. II: Commentary, p. 2268.
32 Eduardo Morales Pérez, "Evaluación a la mitad del camino de la Ronda Uruguay de negociaciones comerciales internacionales", en Boletín de Economía Internacional (Banco de México), enero-marzo, 1989, pp. 39-46.

33 "Declaration of April 1989", en op. cit., Friedrich-Karl Beier y Gerhard Schricker (eds.), pp. 403-405. El Consejo del GATT consideró la petición de laOMPI para que se le admitiera como observador en las reuniones del Consejo y las Sesiones de las Partes Contratantes. Así, un representante de la ompi asistió por primera vez a una reunión del Grupo de Negociación del ADPIC, el 28 de octubre de 1987.

34 Terence P. Stewart (ed.) "Trade-Related Aspects ...", en op. cit., vol. II: Commentary, p. 2272.

35 Major Trade Reform in Several Areas May Fall Victim to Agriculture Impasse, 8 Inside U.S. Trade, Dec. 7, 1990, apud Terence P. Stewart (ed.) "Trade-Related Aspects...", en op. cit., vol. II: Commentary, p. 2276.

36 Por obvias razones, dicho documento es conocido como "texto de Dunkel".

37 United Nations, "Draft Agreement on Trade-Related Aspects...", en Intellectual Property Rights and Foreign Direct..., p. 45.

38 Terence P. Stewart (ed.) "Berne Convention for the Protection of Literary...", en op. cit., volume III: Documents, p. 907.

39 United Nations, "Draft Agreement on Trade-Related Aspects...", en Intellectual Property Rights and Foreign Direct..., p. 46.

40 Ibid., p. 50.

41 Ibid., p. 53.

42 Tal como se especifica en el Apéndice del Convenio de Berna, el cual tiene aplicabilidad en el marco del ADPIC.

43 United Nations, "Draft Agreement on Trade-Related Aspects...”, en Intellectual Property Rights and Foreign Direct..., pp. 69-70. T!: 